\title{
GMR
}

\section{Development of two novel specific SCAR markers by cloning improved RAPD fragments from the medicinal mushroom Ganoderma lucidium (Leysser: Fr) Karst}

\author{
M.A. Khan ${ }^{1}$, J.L. Cheng', Z.Q. Mei ${ }^{1}$, C.L. Wei ${ }^{1,2}$ and J.J. Fu ${ }^{1,2,3}$ \\ ${ }^{1}$ Research Center for Preclinical Medicine, Southwest Medical University, \\ Luzhou, Sichuan, China \\ ${ }^{2}$ State Key Laboratory of Quality Research in Chinese Medicine, \\ Macau University of Science and Technology, Macau, China \\ ${ }^{3}$ Judicial Authentication Center, Southwest Medical University, Luzhou, \\ Sichuan, China \\ Corresponding author: J.J. Fu \\ E-mail: fujunjiang@swmu.edu.cn / fujunjiang@hotmail.com
}

Genet. Mol. Res. 15 (3): gmr.15038536

Received February 5, 2016

Accepted April 11, 2016

Published August 18, 2016

DOI http://dx.doi.org/10.4238/gmr.15038536

Copyright $(C 2016$ The Authors. This is an open-access article distributed under the terms of the Creative Commons Attribution ShareAlike (CC BY-SA) 4.0 License.

\begin{abstract}
Development of sequence-characterized amplified region (SCAR) markers from random-amplified polymorphic DNA (RAPD) fragments is a valuable molecular approach for the genetic identification of different species. By using SCAR markers, molecular analysis is reduced to a simple polymerase chain reaction (PCR) analysis using primers designed from the amplicon sequence of RAPD. In this study, the DNA fragments from an improved RAPD amplification of Ganoderma species were cloned into a pGM-T vector; positive clones were identified by PCR amplification and enzymatic digestion, and
\end{abstract}


finally, DNA fragments were sequenced using the Sanger sequencing method for developing the SCAR markers. Two SCAR markers, named LZ4-1 with 534 nucleotides, and LZ5-2 with 337 nucleotides were identified, which are specific to Ganoderma lucidium (Leysser: Fr) Karst species. BLAST of these two nucleotide sequences in the GenBank database showed no identity to other species. We deposited these sequences into the GenBank database (LZ4-1 accession No. KM391933, LZ5-2 accession No. KM391934). PCR assays confirmed them as novel molecular markers for G. lucidium (Leysser: Fr) Karst, which might be used for genetic authentication of adulterant samples. Thus, our study developed two specific SCAR markers for identifying and distinguishing the medicinal mushroom G. lucidium (Leysser: Fr) Karst from other Ganoderma species.

Key words: Molecular markers; Ganoderma lucidum; Adulterant; Random-amplified polymorphic DNA; Species specific-authentication; Sequence-characterized amplified region

\section{INTRODUCTION}

Mushrooms of the Ganoderma species have been used as traditional medicine for more than 2000 years in East Asia, especially in China. At present, the Ganoderma species is well known globally as a popular alternative medicine, and is commonly known as 'língzhī' (Chinese name) or 'Reishi' (Japanese name). Due to their significant medicinal importance, mushrooms of the Ganoderma species have gained noticeable interest from biomedical researchers. A number of studies have revealed the medicinal values of Ganoderma mushrooms against various life-threatening diseases and health complications like cancer, immunodeficiency, cardiovascular complications, diabetes, hepatic disease, neurodegeneration, and infectious disease (Hajjaj et al., 2005; Paterson, 2006; Ma et al., 2011; Chu et al., 2012; Tie et al., 2012; Xiao et al., 2012; Boh, 2013; Wang et al., 2013; Wu et al., 2013; Yue et al., 2013). There are numerous variations in the size, shape, and color of Ganoderma mushrooms, and they differ in biological properties as well. G. lucidium (Leysser: Fr) Karst is regarded as the most important species of this genus and has often been reported to have significant medicinal importance. Identifying G. lucidum from other Ganoderma species is a difficult task as the morphological differences are not always consistent, and there are intra-species variations as well. Development of G. lucidum-specific molecular markers is thus important to overcome this identification problem.

A number of molecular techniques have been developed in the era of modern biotechnological science in the last 30-40 years. These include random amplified polymorphic DNA (RAPD), simple sequence repeat, inter-simple sequence repeat (ISSR), and amplified fragment length polymorphism analysis (Williams et al., 1990; Agarwal et al., 2008; Bhat et al., 2012; Kumla et al., 2012; Noormohammadi et al., 2013; Fu et al., 2013; Shakeel et al., 2013). These techniques are generally used for genetic characterization of organisms. The sequencecharacterized amplified region (SCAR) marker is one of the stable markers that is generally derived from RAPD (Dnyaneshwar et al., 2006; Li et al., 2010; Rajesh et al., 2013; Fu et al., 2015; Zhang et al., 2015; Mei et al., 2015; Cheng et al., 2016). These markers reveal higher

Genetics and Molecular Research 15 (3): gmr.15038536 
levels of polymorphism due to higher annealing temperatures and longer primer sequence specificity (Kumla et al., 2012; Yang et al., 2013). By using SCAR markers, molecular analysis is reduced to a simple PCR analysis using PCR primers designed from sequences of RAPD amplicons (Kumla et al., 2012; Rajesh et al., 2013). In a previous study, we have genetically characterized members of the Ganoderma species, collected from different locations in China by using an improved RAPD analysis (Mei et al., 2014). Here, we have developed SCAR markers after cloning RAPD fragments specific to G. lucidium (Leysser: Fr) Karst.

\section{MATERIAL AND METHODS}

\section{Extraction of DNA from mushrooms of Ganoderma species}

DNA was extracted from different samples of Ganoderma species (Table 1) as previously described (Fu et al., 2013; Mei et al., 2014). DNA samples were then diluted to a final concentration of $10 \mathrm{ng} / \mu \mathrm{L}$, and stored at $-20^{\circ} \mathrm{C}$ until required. The sequence for the RAPD primer used for SBS-I10 is 5'-ACAACGCGAG-3'.

Table 1. Ganoderma samples used for RAPD-SCAR analysis.

\begin{tabular}{l|l|l|l}
\hline No. & Accession name & Sources of Ganoderma & Deposit No. \\
\hline 1 & Ganoderma gibbosum (Blumii et Nees) Patouillard & Guangdong Culture Collection Center & GIM5.6 \\
\hline 2 & Ganoderma tropicum (Jungh.) Bres. & Guangdong Culture Collection Center & GIM5.289 \\
\hline 3 & Ganoderma applanatum (Pers. ex Wullr) Pat & Guangdong Culture Collection Center & GIM5.282 \\
\hline 4 & Ganoderma australe (Fr.) Pat & Guangdong Culture Collection Center & GIM5.288 \\
\hline 5 & Ganoderma sinense & Inst. Microbiology of Chinese Academy of Sciences & CGMCC5.0069 \\
\hline 6 & G. lucidum HG & Inst. Edible Fungi of Fujian academy of Agric. Sciences & ACCC51329 \\
\hline 7 & Ganoderma lucidum (Curtis) P. Karst & Inst. Edible Fungi of Fujian Academy of Agric. Sciences & CFCC85862 \\
\hline 9 & Ganoderma lucidium & Inst. Microbiology of Chinese Academy of Sciences & CGMCC5.0026 \\
\hline 10 & Ganoderma neojaponicum Imazeki & Beijing Agricultural University & CFCC87599 \\
\hline
\end{tabular}

\section{Amplification and isolation of improved RAPD fragments}

The improved RAPD PCR was performed with random primer for SBS-I10 using DNA from 10 Ganoderma species (mentioned in Table 1). A 15- $\mu \mathrm{L}$ reaction comprising 7.5 $\mu \mathrm{L} 2 \mathrm{X}$ Taq PCR MasterMix (Tiangen Biotech, Beijing, China), $1.5 \mu \mathrm{L} 2.5 \mu \mathrm{M}$ RAPD primer SBS-I10, 1.5 $\mu \mathrm{L}$ genomic DNA, and $4.5 \mu \mathrm{LddH_{2 }} \mathrm{O}$, was set up. Amplification reactions were performed on the "Applied Biosystems Veriti ${ }^{\circledR}$ 96-Well Thermal Cycler" (Life Technology, USA). The following reaction conditions were used: initial denaturation at $95^{\circ} \mathrm{C}$ for $90 \mathrm{~s}, 40$ cycles of denaturation at $94^{\circ} \mathrm{C}$ for $40 \mathrm{~s}$, annealing at $36^{\circ} \mathrm{C}$ for $60 \mathrm{~s}$ with the RAMP rate from annealing to extension adjusted to $0.125^{\circ} \mathrm{C} / \mathrm{s}\left(5 \%\right.$ ramp rate), and extension at $72^{\circ} \mathrm{C}$ for $90 \mathrm{~s}$, followed by a final extension step at $72^{\circ} \mathrm{C}$ for $5 \mathrm{~min}$. PCR products were separated on $1.5 \%$ agarose gel electrophoresis for $40 \mathrm{~min}$. The bright bands were excised from the agarose gel and purified with the TIANgel Mini Purification Kit (DP209, Tiangen Biotech) according to the manufacturer's protocol.

Genetics and Molecular Research 15 (3): gmr.15038536 


\section{DNA cloning}

The purified DNA fragments were ligated into a pGM-T vector (T vector, No. VT202, Tiangen) at $18^{\circ} \mathrm{C}$ for $8-10 \mathrm{~h}$, transformed into DH5 $\alpha$ Escherichia coli competent cells, and cultured overnight at $37^{\circ} \mathrm{C}$.

\section{Screening and sequencing of inserted DNA fragments}

Three methods were used for positive clone screening: white/blue screening, PCR amplification, and DNA digestion. The recombinant clones were seeded on LB agar plates containing $100 \mu \mathrm{g} / \mu \mathrm{L}$ ampicillin, $40 \mathrm{mg} X$-gal and $160 \mu \mathrm{g}$ IPTG. White colonies were screened out by blue/white screening. The presence of the correct insert was verified by PCR amplification using the T7/SP6 primer pair (T7 primer: 5'-TAATACGACTCACTATAGGG-3', SP6 primer: 5'-ATTTAGGTGACACTATAGAA-3'), and by EcoRI digestion (Fu, 2012; Yang et al., 2013, 2014; Fu et al., 2015). The cloned DNA fragments of the correct size were then sequenced by the Sanger method.

\section{Analysis of homology by bioinformatics}

The homology of sequenced DNA with existing sequences in different species, was examined and analyzed by the online program BLAST (http://www.ncbi.nlm.nih.gov/ BLAST/) (Yang et al., 2013; Fu et al., 2015).

\section{SCAR primer design}

The nucleotide sequence of each cloned RAPD fragment was used to design pairs of SCAR primers using the online Primer 3 program (http://bioinfo.ut.ee/primer3-0.4.0/primer3/) and the sequences of each primer are listed in Table 2 (Yang et al., 2013; Fu et al., 2015).

Table 2. Sequences of SCAR primers, annealing temperatures, and product size.

\begin{tabular}{l|l|l|l|l|c|c}
\hline SCAR & 5 '-primer & Sequence $\left(5^{\prime}-3\right.$ ') & 3'-primer & Sequence $\left(5^{\prime}-3^{\prime}\right)$ & Size $(\mathrm{bp})$ & Tm $\left({ }^{\circ} \mathrm{C}\right)$ \\
\hline LZ4-1 & LZ4-1L & TACAGCGTTGCGAATACCCT & LZ4-1R & AAAAGTGAGAACAACGGCGC & 304 & 60 \\
\hline Z5-2 & LZ5-2L & AATGCTGGGCGAAATGAACG & LZ5-2R & GGTTTTAGCGCCTTCCAGTG & 337 & 60 \\
\hline
\end{tabular}

Tm, melting temperature.

\section{Development of SCAR markers}

To develop SCAR markers, PCR amplification was performed, where the composition of a $10-\mu \mathrm{L}$ reaction was as follows: $5 \mu \mathrm{L} 2 \mathrm{X}$ Taq PCR MasterMix (Tiangen Biotech), $1 \mu \mathrm{L} 2.5$ $\mu \mathrm{M}$ SCAR primers (each pair) and $1 \mu \mathrm{L}$ genomic DNA (10 ng), and $3 \mu \mathrm{L} \mathrm{ddH}_{2} \mathrm{O}$. PCR was performed on the "Applied Biosystems Veriti ${ }^{\circledR}$ 96-Well Thermal Cycler" (Life Technology) with an initial pre-denaturation for $90 \mathrm{~s}$ at $95^{\circ} \mathrm{C}$, followed by 35 cycles of denaturation at $94^{\circ} \mathrm{C}$ for $40 \mathrm{~s}$, annealing at $60^{\circ}$ or $62^{\circ} \mathrm{C}$ for $30 \mathrm{~s}$, and extension at $72^{\circ} \mathrm{C}$ for $40 \mathrm{~s}$. The final extension step was performed at $72^{\circ} \mathrm{C}$ for 5 min. The sequences of both pairs of SCAR primers, the amplified length, and the PCR condition are listed in Table 2. To distinguish between the varieties of Ganoderma species and other species of medicinal plants, SCAR 
analysis was performed with 23 DNA samples as templates. These included ten samples of previously described Ganoderma species (Mei et al., 2014), two samples of Dimocarpus longan collected from Fujian and Hainan, described by Yang et al. (2013), two samples of Lonicera japonica collected from Guangdong and Hubei, described by Fu et al. (2013), one Gardenia jasminoides, one Litchi chinensis from Guangdong, one Dimocarpus confinis from Guangxi, one Canarium album from Luzhou City in Sichuan Province, Gastrodia elata collected from Liangshan City in Sichuan Province, one Penthorum sedoides, Penthorum chinense collected from Gulin County of Luzhou City in Sichuan Province, and Viola philippica, described by Yang et al. (2013), and one Angelica sinensis from Sichuan Province (Zhang et al., 2015).

The amplified PCR products were separated by electrophoresis on $1.0 \%$ agarose gel in $1 \mathrm{X}$ TAE buffer at $120 \mathrm{~V}$ for $40 \mathrm{~min}$. The gels were visualized by staining with 0.5 $\mu \mathrm{g} / \mathrm{mL}$ ethidium bromide, and the images were documented with the ChemiDoc XRS (Bio-Rad, USA).

\section{RESULTS}

\section{Isolation of RAPD fragments}

The RAPD primer SBC-I10 was used to improve RAPD amplification from ten DNA samples of Ganoderma species (Table 1). The results are shown in Figure 1A, the blue arrows indicate bands specific to G. lucidium (Leysser: Fr) Karst. These were cut from agarose gel, and labeled with LZ4 and LZ5, respectively. The DNA on agarose gel was purified and eluted in $20 \mu \mathrm{L} \mathrm{ddH_{2 }}$ O. To check DNA quality and determine the quantity for ligation, the purified DNAs were again run on an agarose gel by loading $2 \mu \mathrm{L}$ purified PCR products and $0.5 \mu \mathrm{L}$ T-vector into each well. The results are shown in Figure 1B.

\section{DNA cloning and sequencing}

According to the DNA quantity shown in Figure 1B, an appropriate amount of PCR product and T-vector were ligated, transformed into DH5 $\alpha$ E. coli competent cells, and first screened by the blue/white method. The positive clones were then identified by PCR amplification (Figure 1C). The positive clones in Figure 1 (red lanes) were further used for plasmid extraction followed by EcoRI enzyme digestion (Figure 1D). In lanes 2 and 4 of Figure 1D, the clones LZ4-1 and LZ5-2, which showed $~ 600$ - and $~ 400-b p$ inserted DNA fragments, respectively, were subjected to sequencing.

\section{Sequencing information and characterization of Ganoderma species-specific RAPD fragments}

Sequencing of the four above-mentioned cloned RAPD fragments revealed that the clone LZ4-1 consisted of 534 nucleotides and was deposited into GenBank with the accession No. KM391933 (Figure 2A), whereas the clone LZ5-2 consisted of 337 nucleotides, and was deposited into GenBank with the accession No. KM391934 (Figure 2B). BLAST of these two nucleotide sequences in GenBank database did not reveal any matching sequences (data not shown).

Genetics and Molecular Research 15 (3): gmr.15038536 
A

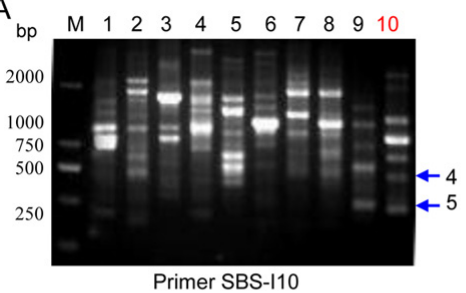

C

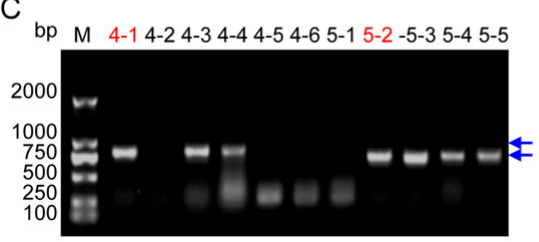

B

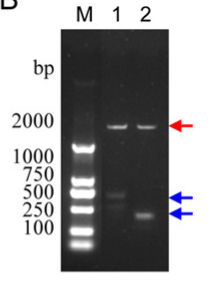

D $\quad M \begin{array}{llll}1 & 2 & 3 & 4\end{array}$

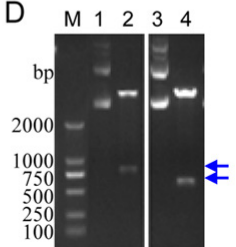

Figure 1. Amplification, DNA cloning, and positive clone identification from improved RAPD fragments. A. Improved RAPD from DNA samples of Ganoderma species. Lanes 1-10 are the different Ganoderma species samples listed in Table 1. The blue arrows in lane 10 (red) indicate the bands used for cutting, "4" is the LZ4 fragment and " 5 ' is the LZ5 fragment. B. Quality and quantity examination of improved RAPD fragments purified from agarose gel. The blue arrows indicate the fragments LZ4 and LZ5, respectively. The red arrow indicates the T-vector. C. Clone identification of RAPD DNA fragments LZ4 and LZ5 by PCR. Lanes 4-1-4-6 indicate different clones from LZ4, and lanes 5-2-5-5 indicate different clones from LZ5. Blue arrows indicate the amplified fragments LZ4 and LZ5, respectively. Clones LZ4-1 and LZ5-2 marked in red were picked to extract plasmid DNA. D. Identification of positive clones by plasmid DNA digestion. Lanes 1 and 2 indicate clone LZ4-1 plasmid DNA without or with EcoRI digestion. Lanes 3 and 4 indicate clone LZ5-2 plasmid DNA without or with EcoRI digestion. The blue arrows indicate the expected insert positions of the RAPD DNA fragments. Lane M indicates DNA molecular weight marker DL2000 with the fragment size (bp) 2000, 1000, 750, 500, 250, 100.
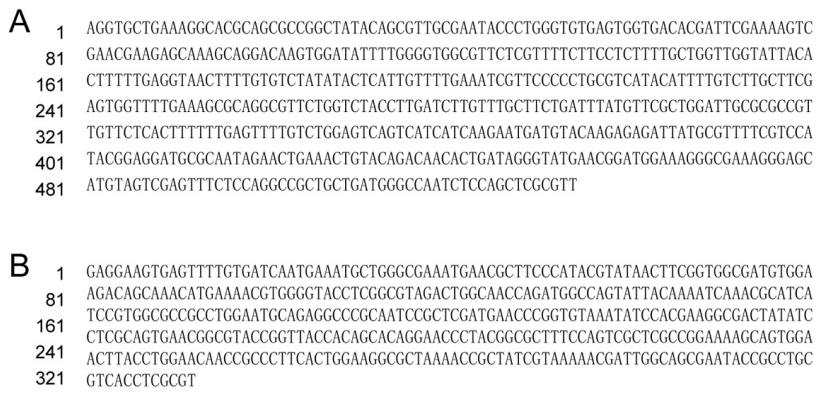

Figure 2. Clone sequence information by Sanger-sequencing. A. Sequences of clone LZ4-1 with 534 bp. B. Sequences of clone LZ5-2 with 337 bp.

\section{Development of G. lucidium (Leysser: Fr) Karst-specific SCAR markers}

To generate stable diagnostic Ganoderma species-specific SCAR markers from our RAPD markers, two pairs of primers (Table 2) were designed and synthesized based on the cloned sequences. The designed SCAR primer pairs were then used in amplification reactions with the genomic DNA from 23 collected DNA samples as templates to assess speciesspecific amplification. The results are shown in Figure 3, both SCAR markers, LZ4-1 and LZ5-2 only amplified a band of the expected size from the sample G. lucidium (Leysser: Fr)

Genetics and Molecular Research 15 (3): gmr.15038536 
Karst, which was one of ten Ganoderma species tested (lane 10 of Figure 3A and B). None of the other medicinal species showed any amplification. These results indicate that these two SCAR markers are sample-specific, and not species-specific. The lack of this specific amplicon in other Ganoderma species indicates the efficacy of these markers in distinguishing the Ganoderma samples from each other.

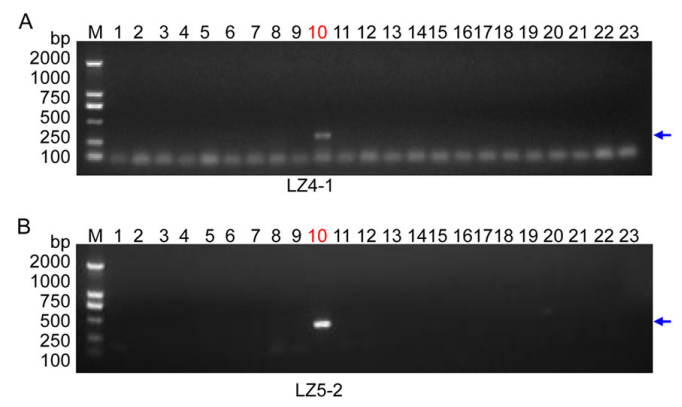

Figure 3. Development of RAPD-SCAR markers for LZ4-1 and LZ5-2. A. SCAR marker LZ4-1. B. SCAR marker LZ5-2. Lanes 1-10 indicate different Ganoderma species samples listed in Table 1. Lanes 11-23 are DNA samples described in Material and Methods. Lanes 11 and 12 are two samples of D. longan; lanes 13 and 14 are two samples of L. japonica; lane 15 is one sample of G. jasminoides; lane 16 is one sample of L. chinesis; lane 17 is one sample of D. confinis; lane 18 is one sample of C. album; lane 19 is one sample of Gastrodia elata. Lane 20 is one sample of $P$. sedoides; lane 21 is one sample of $P$. chinense; lane 22 is one sample of $V$. philippica; lane 22 is one sample of A. sinensis; lane 23 is the negative control without any DNA. The blue arrows indicate the expected PCR products. Lane $M$ indicates the DNA molecular weight marker DL2000.

\section{DISCUSSION}

G. lucidum is frequently used in Traditional Chinese Medicine (TCM), and is known to have anti-oxidative effects, a therapeutic effect on insulin resistance, and reduced risk of cancers. It also can help to treat a variety of conditions associated with metabolic syndromes.

The development of molecular marker technologies has revolutionized the identification and characterization of any organism. These techniques are especially useful to systematic biologists, and are help to solve identification problems at species and population levels. RAPD is one of the widely used techniques that is used in the genetic characterization and identification of species. RAPD is easy to handle, can reveal high degrees of polymorphisms, and does not require DNA sequence information of the investigated species (Williams et al., 1990; Fu et al., 2013; Shakeel et al., 2013). Developed in the 1990s, RAPD is still a popular molecular marker technique, and is presently being used with a significant emphasis. A number of recent studies have reported the potential of traditional RAPD and improved RAPD for the genetic characterization and identification of different plant or animal species (Bhat et al., 2012; Kumla et al., 2012; Fu et al., 2013; Noormohammadi et al., 2013; Shakeel et al., 2013; Mei et al., 2014). When the RAPD technique is combined with the SCAR marker technology, specificity and stability is significantly improved, which makes genetic identification and authentication more convenient and efficient for testing different alleles (Rajesh et al., 2013; Yang et al., 2013, 2014; Mei et al., 2015).

In this study, we collected different species of Ganoderma mushrooms, extracted their DNA and amplified it using the improved RAPD technique. The RAPD fragments

Genetics and Molecular Research 15 (3): gmr.15038536 
were then cloned into T-vector to develop two SCAR markers (LZ4-1 and LZ5-2). By PCR amplification of different samples, these markers were demonstrated as highly specific to $G$. lucidium (Leysser: Fr) Karst species (Figure 3), which we collected from Inst. Wensheng Edible Fungi in Shantou City, where they are cultivated from different kinds of Ganoderma species. These SCAR markers reveal higher levels of polymorphism due to higher annealing temperatures and longer primer sequence specificity (Kumla et al., 2012). This is the first report on SCAR marker development based on RAPD fragments, for the identification of $G$. lucidium (Leysser: Fr) Karst species from other Ganoderma species. In a previous study, Su et al. (2007) developed a 'strain-specific' G. lucidum ISSR-based SCAR marker, which could identify certain strains of G. lucidum, but it was not a species-specific marker. RAPD-SCAR markers have been successfully developed for the identification of some other organisms, including plants, animals, and microbes (Jiang et al., 2009; Dutta et al., 2012; Lee et al., 2013; Yang et al., 2013, 2014, Fu et al., 2015; Zhang et al., 2015; Mei et al., 2015).

The SCAR marker LZ4-1 consisted of 534 nucleotides and has been deposited into GenBank with the accession No. KM391933, and LZ5-2 consisted of 337 nucleotides and has been deposited with the accession No. KM391934. Both these SCAR markers are specific to $G$. lucidum (Leysser: Fr) Karst species, but are absent in other species of the Ganoderma genus. There are huge variations in the genetic material of different Ganoderma species. In a previous study, by using improved RAPD, we reported 93\% polymorphism among different Ganoderma species or between G. lucidum strains (Mei et al., 2014). Another study by Zhao et al. (2003) reported 80$100 \%$ genetic polymorphism among different Ganoderma species. These high levels of genetic polymorphism reflect the high level of diversity in the morphology and chemical composition within different species of Ganoderma. The unique genetic characteristics of G. lucidum might influence the morphological and chemical constituents of this mushroom, making it medicinally important and beneficial to health. Studies indicated that G. lucidum is superior to other Ganoderma species in nutritional and medicinal aspects (Paterson, 2006; Sanodiya et al., 2009).

BLAST of these two nucleotide sequences (LZ4-1 and LZ5-2) in the GenBank database did not show any identity to sequences from any species, indicating the novelty of these two SCAR markers for G. lucidium (Leysser: Fr) Karst. Using these molecular markers will simplify the authentic identification of G. lucidum, which has a notable medicinal importance for the treatment of several life-threatening diseases.

\section{CONCLUSION}

We have successfully developed the SCAR markers, LZ4-1 and LZ5-2, by cloning the improved RAPD fragments specific to G. lucidium (Leysser: Fr) Karst. These novel specific SCAR markers can be used for the specific identification of the popular medicinal mushroom, G. lucidum family from adulterant samples.

\section{Conflicts of interest}

The authors declare no conflict of interest.

\section{ACKNOWLEDGMENTS}

Research supported in part by the Science and Technology Innovation Team of Colleges

Genetics and Molecular Research 15 (3): gmr.15038536 
and Universities in Sichuan Province (\#13TD0032) and the Applied Basic Research Program of Science and Technology Department of Sichuan Province (\#14JC0797, \#2015JY0038).

\section{REFERENCES}

Agarwal M, Shrivastava N and Padh H (2008). Advances in molecular marker techniques and their applications in plant sciences. Plant Cell Rep. 27: 617-631.http://dx.doi.org/10.1007/s00299-008-0507-z

Bhat AA, Haniffa MA, Divya PR, Gopalakrishnan A, et al. (2012). Molecular characterization of eight Indian Snakehead species (Pisces: Perciformes Channidae) using RAPD markers. Mol. Biol. Rep. 39: 4267-4273. http://dx.doi. org/10.1007/s11033-011-1213-4

Boh B (2013). Ganoderma lucidum: a potential for biotechnological production of anti-cancer and immunomodulatory drugs. Recent Patents Anticancer. Drug Discov. 8: 255-287. http://dx.doi.org/10.2174/1574891X113089990036

Cheng JL, Yin ZC, Mei ZQ, Wei CL, et al. (2016). Development and significance of SCAR marker QG12-5 for Canarium album (Lour.) Raeusch by molecular cloning from improved RAPD amplification. Genet. Mol. Res. 15: in press.

Chu TT, Benzie IF, Lam CW, Fok BS, et al. (2012). Study of potential cardioprotective effects of Ganoderma lucidum (Lingzhi): results of a controlled human intervention trial. Br. J. Nutr. 107: 1017-1027. http://dx.doi.org/10.1017/ $\underline{\mathrm{S} 0007114511003795}$

Dnyaneshwar W, Preeti C, Kalpana J and Bhushan P (2006). Development and application of RAPD-SCAR marker for identification of Phyllanthus emblica LINN. Biol. Pharm. Bull. 29: 2313-2316.http://dx.doi.org/10.1248/bpb.29.2313

Dutta SR, Kar PK, Srivastava AK, Sinha MK, et al. (2012). Identification of RAPD and SCAR markers associated with yield traits in the Indian tropical tasar silkworm Antheraea mylitta drury. Genet. Mol. Biol. 35: 743-751. http://dx.doi. org $/ 10.1590 / \mathrm{S} 1415-47572012005000059$

Fu JJ (2012). Short protocols in medical molecular biology. China Medical Science Press, Beijing.

Fu J, Yang L, Khan MA and Mei Z (2013). Genetic characterization and authentication of Lonicera japonica Thunb. by using improved RAPD analysis. Mol. Biol. Rep. 40: 5993-5999. http://dx.doi.org/10.1007/s11033-013-2703-3

Fu JJ, Mei ZQ, Tania M, Yang LQ, et al. (2015). Development of RAPD-SCAR markers for different Ganoderma species authentication by improved RAPD amplification and molecular cloning. Genet. Mol. Res. 14: 5667-5676. http:// dx.doi.org/10.4238/2015.May.25.19

Hajjaj H, Macé C, Roberts M, Niederberger P, et al. (2005). Effect of 26-oxygenosterols from Ganoderma lucidum and their activity as cholesterol synthesis inhibitors. Appl. Environ. Microbiol. 71: 3653-3658.http://dx.doi.org/10.1128/ AEM.71.7.3653-3658.2005

Jiang S, Jianhua X and Li X (2009). A study on the RAPD and SCAR molecular markers of Piper species. J. Agric. Rural Dev. Trop. Subtrops. 110: 127-135.

Kumla S, Doolgindachbaporn S, Sudmoon R and Sattayasai N (2012). Genetic variation, population structure and identification of yellow catfish, Mystus nemurus $(\mathrm{C} \& \mathrm{~V})$ in Thailand using RAPD, ISSR and SCAR marker. Mol. Biol. Rep. 39: 5201-5210. http://dx.doi.org/10.1007/s11033-011-1317-x

Lee DH, Lee SK, Lee SY and Lee JK (2013). Development of SCAR markers for the identification of Phytophthora katsurae causing chestnut ink disease in Korea. Mycobiology 41: 86-93. http://dx.doi.org/10.5941/MYCO.2013.41.2.86

Li SF, Tang SJ and Cai WQ (2010). RAPD-SCAR markers for genetically improved NEW GIFT Nile Tilapia (Oreochromis niloticus niloticus L.) and their application in strain identification. Zool. Res. 31: 147-154. http://dx.doi.org/10.3724/ SP.J.1141.2010.02147

Ma J, Liu C, Chen Y, Jiang J, et al. (2011). Cellular and molecular mechanisms of the Ganoderma applanatum extracts induces apoptosis on SGC-7901 gastric cancer cells. Cell Biochem. Funct. 29: 175-182. http://dx.doi.org/10.1002/ cbf. 1735

Mei Z, Yang L, Khan MA, Yang M, et al. (2014). Genotyping of Ganoderma species by improved random amplified polymorphic DNA (RAPD) and inter-simple sequence repeat (ISSR) analysis. Biochem. Syst. Ecol. 56: 40-48. http:// dx.doi.org/10.1016/j.bse.2014.04.012

Mei Z, Zhou B, Wei C, Cheng J, et al. (2015). Genetic authentication of Gardenia jasminoides Ellis var. grandiflora Nakai by improved RAPD-derived DNA markers. Molecules 20: 20219-20229. http://dx.doi.org/10.3390/ molecules 201119687

Noormohammadi Z, Hasheminejad-Ahangarani Farahani Y, Sheidai M, Ghasemzadeh-Baraki S, et al. (2013). Genetic diversity analysis in Opal cotton hybrids based on SSR, ISSR, and RAPD markers. Genet. Mol. Res. 12: 256-269. http://dx.doi.org/10.4238/2013.January.30.12

Paterson RR (2006). Ganoderma - a therapeutic fungal biofactory. Phytochemistry 67: 1985-2001. http://dx.doi. org/10.1016/j.phytochem.2006.07.004

Genetics and Molecular Research 15 (3): gmr.15038536 
Rajesh MK, Jerard BA, Preethi P, Thomas RJ, et al. (2013). Development of a RAPD-derived SCAR marker associated with tall-type palm trait in coconut. Sci. Hortic. (Amsterdam) 150: 312-316. http://dx.doi.org/10.1016/j. $\underline{\text { scienta.2012.11.023 }}$

Sanodiya BS, Thakur GS, Baghel RK, Prasad GB, et al. (2009). Ganoderma lucidum: a potent pharmacological macrofungus. Curr. Pharm. Biotechnol. 10: 717-742.http://dx.doi.org/10.2174/138920109789978757

Shakeel M, Ilyas M and Kazi M (2013). Evaluation of synthetic hexaploid wheats (derivative of durum wheats and Aegilops tauschii accessions) for studying genetic diversity using randomly amplified polymorphic DNA (RAPD) markers. Mol. Biol. Rep. 40: 21-26. http://dx.doi.org/10.1007/s11033-012-1943-y

$\mathrm{Su}$ H, Wang L, Ge Y, Feng E, et al. (2007). Development of strain-specific SCAR markers for authentication of Ganoderma lucidum. World J. Microbiol. Biotechnol. 24: 1223-1226. http://dx.doi.org/10.1007/s11274-007-9579-0

Tie L, Yang HQ, An Y, Liu SQ, et al. (2012). Ganoderma lucidum polysaccharide accelerates refractory wound healing by inhibition of mitochondrial oxidative stress in type 1 diabetes. Cell. Physiol. Biochem. 29: 583-594.http://dx.doi. org $/ 10.1159 / 000338512$

Wang XF, Li QZ, Bao TW, Cong WR, et al. (2013). In vitro rapid evolution of fungal immunomodulatory proteins by DNA family shuffling. Appl. Microbiol. Biotechnol. 97: 2455-2465. http://dx.doi.org/10.1007/s00253-012-4131-z

Williams JG, Kubelik AR, Livak KJ, Rafalski JA, et al. (1990). DNA polymorphisms amplified by arbitrary primers are useful as genetic markers. Nucleic Acids Res. 18: 6531-6535.http://dx.doi.org/10.1093/nar/18.22.6531

Wu X, Zeng J, Hu J, Liao Q, et al. (2013). Hepatoprotective effects of aqueous extract from Lingzhi or Reishi medicinal mushroom Ganoderma lucidum (higher basidiomycetes) on a-amanitin-induced liver injury in mice. Int. J. Med. Mushrooms 15: 383-391.http://dx.doi.org/10.1615/IntJMedMushr.v15.i4.60

Xiao C, Wu QP, Cai W, Tan JB, et al. (2012). Hypoglycemic effects of Ganoderma lucidum polysaccharides in type 2 diabetic mice. Arch. Pharm. Res. 35: 1793-1801. http://dx.doi.org/10.1007/s12272-012-1012-z

Yang L, Fu S, Khan MA, Zeng W, et al. (2013). Molecular cloning and development of RAPD-SCAR markers for Dimocarpus longan variety authentication. Springerplus 2: 501. http://dx.doi.org/10.1186/2193-1801-2-501

Yang L, Khan MA, Mei Z, Yang M, et al. (2014). Development of RAPD-SCAR markers for Lonicera japonica (Caprifolicaceae) variety authentication by improved RAPD and DNA cloning. Rev. Biol. Trop. 62: 1649-1657. http://dx.doi.org/10.15517/rbt.v62i4.13493

Yue GG, Chan BC, Han XQ, Cheng L, et al. (2013). Immunomodulatory activities of Ganoderma sinense polysaccharides in human immune cells. Nutr. Cancer 65: 765-774.http://dx.doi.org/10.1080/01635581.2013.788725

Zhang C, Mei Z, Cheng J, He Y, et al. (2015). Development of SCAR markers based on improved RAPD amplification fragments and molecular cloning for authentication of herbal medicines Angelica sinensis, Angelica acutiloba and Levisticum officinale. Nat. Prod. Commun. 10: 1743-1747.

Zhao MW, Chen MJ, Wang N, Liang WQ, et al. (2003). Study on genetic relationship among some commercial strains of Ganoderma. J. Nanjing Agric. Univ. 26: 60-63.

Genetics and Molecular Research 15 (3): gmr.15038536 